Article

\title{
Achieving a Good Life Time in a Vertical-Organic-Diode Gas Sensor
}

\author{
Ming-Zhi Dai ${ }^{1}$, Yen-Ho Chen ${ }^{1}$, Ming-Yen Chuang ${ }^{2}$, Hsiao-Wen Zan ${ }^{2, *}$ and Hsin-Fei Meng ${ }^{1}$ \\ 1 Institute of Physics, National Chiao Tung University, Hsinchu 300, Taiwan; \\ E-Mails:whiffet_tw@hotmail.com (M.-Z.D.); patrickyoyo0624@hotmail.com (Y.-H.C.); \\ meng@mail.nctu.edu.tw (H.-F.M.) \\ 2 Department of Photonics and Institute of Electro-Optical Engineering, National Chiao Tung \\ University, Hsinchu 300, Taiwan; E-Mail: a524524524@livemail.tw \\ * Author to whom correspondence should be addressed; E-Mail: hsiaowen@mail.nctu.edu.tw; \\ Tel.: +886-3513-1305; Fax: +886-3573-7681.
}

Received: 15 June 2014; in revised form: 7 August 2014 / Accepted: 26 August 2014 /

Published: 2 September 2014

\begin{abstract}
In this study, we investigate the keys to obtain a sensitive ammonia sensor with high air stability by using a low-cost polythiophene diode with a vertical channel and a porous top electrode. Poly(3-hexylthiophene) (P3HT) and air-stable poly(5,5'-bis(3-dodecyl-2-thienyl)-2,2'-bithiophene) (PQT-12) are both evaluated as the active sensing layer. Two-dimensional current simulation reveals that the proposed device exhibits numerous connected vertical nanometer junctions (VNJ). Due to the de-doping reaction between ammonia molecules and the bulk current flowing through the vertical channel, both PQT-12 and P3HT VNJ-diodes exhibit detection limits of 50-ppb ammonia. The P3HT VNJ-diode, however, becomes unstable after being stored in air for two days. On the contrary, the PQT-12 VNJ-diode keeps an almost unchanged response to 50-ppb ammonia after being stored in air for 25 days. The improved storage lifetime of an organic-semiconductor-based gas sensor in air is successfully demonstrated.
\end{abstract}

Keywords: ammonia; gas sensor; polythiophene; solid-state sensors 


\section{Introduction}

Solid-state gas sensors have drawn considerable attention for their applications in environmental pollution monitoring [1], toxic or explosive gas detection [2], food condition tracking [3] and non-invasive diagnostics through breath analysis [4-6]. Among these applications, sensors based on organic semiconductor (OSC) materials are particularly promising because of their low-cost process, room-temperature operation and wide selection of material properties [4,7]. However, when OSC materials are stored in air, oxidation due to oxygen and moisture is known to destroy the electric property in OSC materials within a few days [8,9]. Recently, researchers proposed various air-stable OSC materials and successfully demonstrated air-stable organic thin-film transistors (OTFTs) [10-12]. A 120-day storage time was reported for OTFT with an air-stable OSC layer. In an OSC-based gas sensor, however, the air stability after long-term storage has been not reported yet.

In this work, we studied the air stability of a sensitive ammonia gas sensor based on a vertical organic diode. Two kinds of polythiophene materials are used in the proposed sensor. One is poly(3-hexylthiophene) (P3HT); the other is air-stable poly(5,5'-bis(3-dodecyl-2-thienyl)2,2'-bithiophene) (PQT-12). In recent years, abundant research focused on developing nanostructure gas sensors [13-16]. Sensors with a nanostructure can increase the surface-to-volume ratio and, thus, lead to higher performance. Chen shows that under ultraviolet light illumination during gas sensing, single-walled carbon nanotubes can detect ammonia, nitric oxide and nitrogen dioxide in parts per trillion level [17]. Besides, Hassan reports that vertical zinc oxide nanorod arrays exhibit high sensitivity to hydrogen [18]. Here, instead of changing the sensing layer into a nanostructure, we develop an electrode with nanopores to form vertical nano-channels in the sensing layer. In our previous work, we had used a P3HT-based vertical diode with a porous top electrode to detect the breath ammonia of rats [19]. The vertical diode exhibits numerous vertical nanometer junctions and is named the vertical nanometer junction (VNJ)-diode. In this work, we demonstrate that the P3HT VNJ-diode exhibits air stability only for 1-2 days. Using PQT-12 to replace P3HT, we successfully realize a sensitive ammonia sensor with a detection limit of $50 \mathrm{ppb}$ after being stored in air for 25 days. In a previous report, a resistor-type sensor using PQT-12 film was found to have almost no response to $1000 \mathrm{ppm}$ ammonia [20]. In that work, the addition of carbon nanotubes (CNTs) into PQT-12 can greatly improve the sensing response. In this work, we demonstrate that using the VNJ-diode structure, the bulk current flowing through PQT-12 responds to 50-ppb ammonia. Together with the simple structure and low-cost process, the improved air stability demonstrated in this work facilitates the future commercialization of OSC-based gas sensors.

\section{Experimental Section}

The structure of the proposed VNJ-diode is shown in Figure 1a. Figure $1 \mathrm{~b}$ shows the simulated current distribution of the P3HT VNJ-diode. A Silvaco TCAD simulator (Silvaco Inc., Santa Clara, CA, USA) was used to perform the simulation with the parameters provided in [21]. The molecular structures of two polythiophene-based organic semiconductor materials, P3HT and PQT-12, are shown in Figure 1c,d, respectively. 
Figure 1. (a) The structure of the polythiophene vertical nanometer junction (VNJ)-diode; (b) the simulated current distribution of the poly(3-hexylthiophene) (P3HT) VNJ-diode. The molecular structures of (c) P3HT and (d) poly[5,5'-bis(3-dodecyl-2-thienyl)2,2'-bithiophene] (PQT-12).

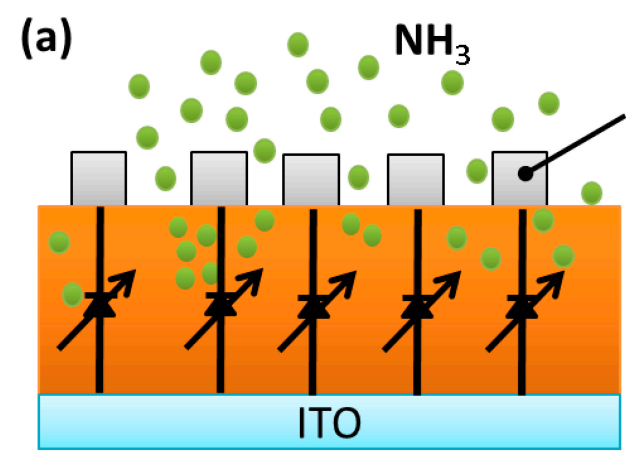

(b)

(c)

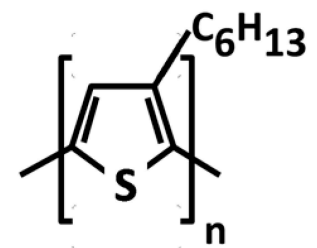

P3HT (d)

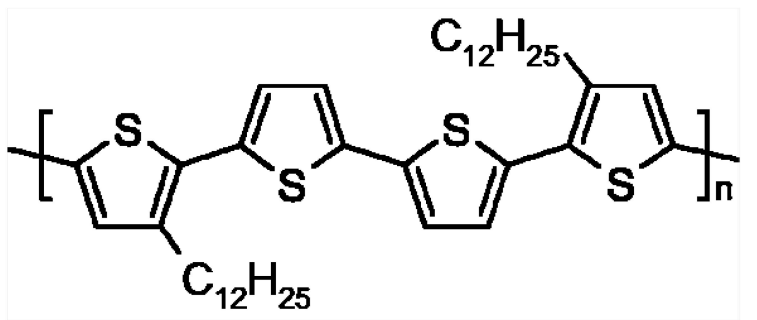

PQT-12

Figure 2 shows the fabrication process of the VNJ-diode. A glass substrate with patterned bottom electrode, indium tin oxide (ITO), is prepared (purchased from Dong Guang, resistivity $7 \Omega /$ square). The ITO electrode is treated by $100 \mathrm{~W}$ oxygen plasma for $15 \mathrm{~min}$. For the PQT-12 VNJ-diode, PQT-12 (American Dye Source, Inc., Quebec, Canada, molecular weight 15,000-50,000) material dissolved in chloroform (purchased from Aldrich, St. Louis, MO, USA) (0.8 wt \%) was spun coated on a substrate to form a PQT-12 layer. After the PQT-12 film was annealed at $140{ }^{\circ} \mathrm{C}$ for $30 \mathrm{~min}$, the thin-film PQT-12 was spin-rinsed with $p$-xylene (purchased from Aldrich). The resulting PQT-12 layer exhibits a thickness of 60-100 nm. The substrate was then submerged into a dilute ethanol solution of negatively charged polystyrene (PS) spheres (Fluka). PS spheres with a diameter of $200 \mathrm{~nm}$ were adsorbed on the substrate as the shadow mask. Optimized sphere densities (about $5 \# / \mu \mathrm{m}^{2}$ ) were obtained by using the concentration of the PS sphere as $0.24 \mathrm{wt} \%$ with $40 \mathrm{~s}$ soaking time. The wet substrate was dipped into boiling isopropyl alcohol (IPA) for $10 \mathrm{~s}$. The substrate was blow-dried immediately after dipping into IPA. Aluminum (Al) of $40 \mathrm{~nm}$ was thermal evaporated as the top electrode with an active area of $1 \mathrm{~mm}^{2}$. Adhesive tape (Scotch, $3 \mathrm{M}$ ) was used to remove the PS spheres. An aluminum top electrode with high-density nanopores was formed. For the P3HT VNJ-diode, P3HT (Rieke Metals, $2.5 \mathrm{wt} \%$ in chlorobenzene, molecular weight 50,000-70,000) was spun coated on ITO substrate. The P3HT film was annealed at $200{ }^{\circ} \mathrm{C}$ for $10 \mathrm{~min}$. After the P3HT layer was spin-rinsed with $p$-xylene, a film thickness of $40 \mathrm{~nm}$ was formed. The optimized PS sphere density (about $5 \# / \mu \mathrm{m}^{2}$ ) can be also obtained by using ethanol with the 0.24 wt \% PS sphere and 40-s soaking time. 
Figure 2. The fabrication process of the P3HT VNJ-diode. (a) Polystyrene (PS) spheres adsorbed onto P3HT; (b) aluminum of $40 \mathrm{~nm}$ was deposited as the metal electrode; and (c) the schematic diagram and the SEM image of the top electrode with nano-pores.

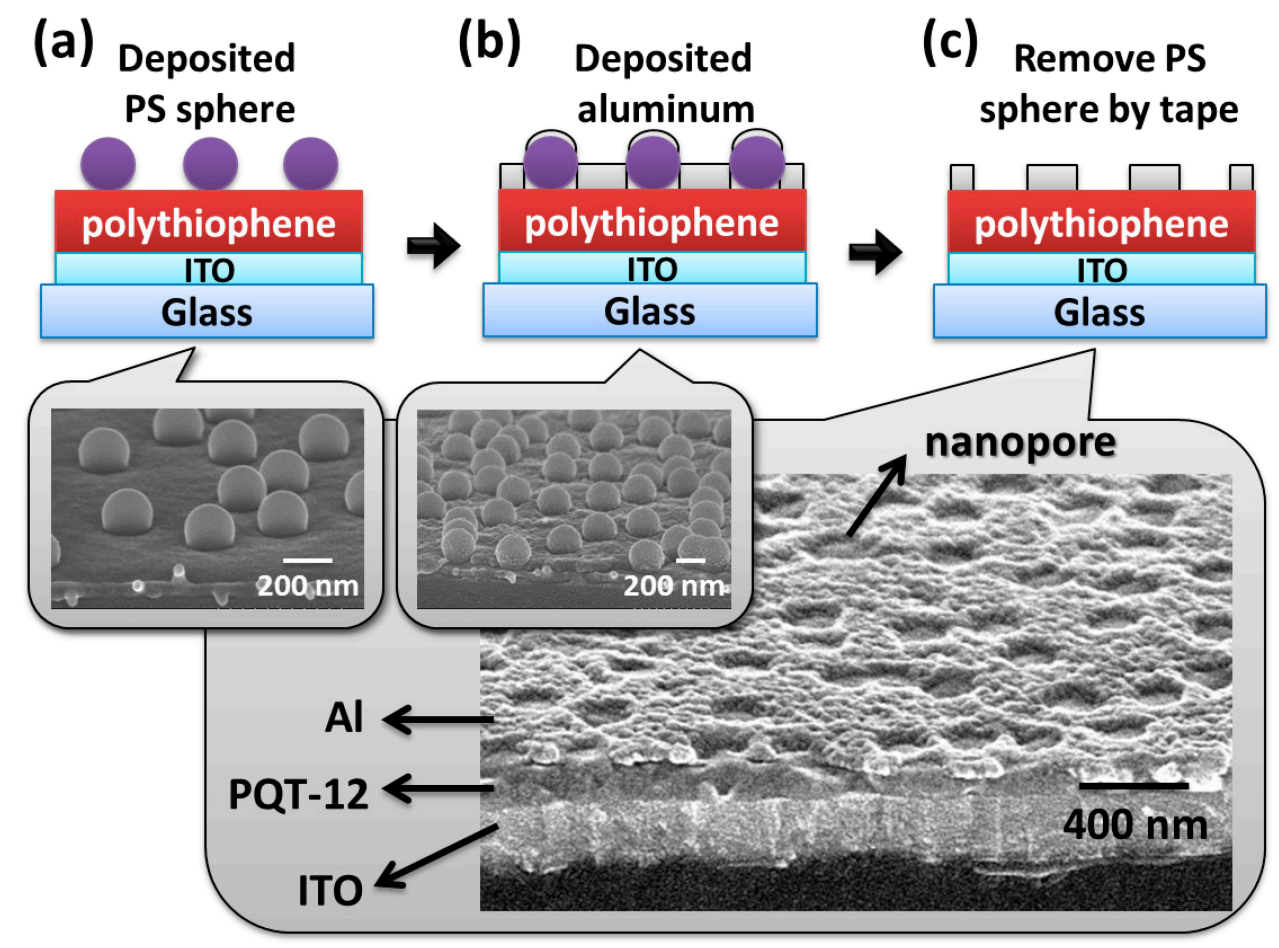

The PQT-12 VNJ-diode or the P3HT VNJ-diode was placed in a micro-fluid sensing chamber containing a high purity (99.9999\%) nitrogen gas. We used an electrical syringe pump to inject the $100 \mathrm{ppm}$ ammonia (NH3) into a tube to mix with high-purity nitrogen gas. The nitrogen gas flow was controlled by a mass-flow controller, and the ammonia concentration was obtained by adjusting the injection speed of the syringe pump. The gas mixture then entered the micro-fluid system.

\section{Results and Discussion}

The simulated two-dimensional current distribution of the VNJ-diode is shown in Figure 1b [21]. Because of the low conductivity of polythiophene materials, such as P3HT or PQT-12, the vertical current flows are limited within the regions with overlapping top and bottom electrodes. Hence, the VNJ-diode operates like vertical nanometer junctions connected in parallel.

Figure $3 \mathrm{a}$ shows the current densities as a function of the applied bias $(\mathrm{J}-\mathrm{V})$ of the PQT-12 VNJ-diode before ammonia sensing (solid line) and after 200-s, 500-ppb ammonia sensing (dashed line). Those of the P3HT VNJ-diode are shown in Figure 3b. Because the highest-occupied molecular-orbital (HOMO) level of PQT-12 is $5.3 \mathrm{eV}$, hole injection from oxygen-plasma-treated ITO (the work function is about $5 \mathrm{eV}$ ) to PQT-12 exhibits an energy barrier. Hence, in Figure 3a, the current density at low biasing voltage is small. For the P3HT VNJ-diode, the hole injection barrier is small, since the HOMO level of P3HT $(5 \mathrm{eV})$ is similar to the work function of oxygen-plasma-treated ITO. Regardless of the different hole injection conditions, both the P3HT and PQT-12 VNJ-diodes exhibit obvious current drops after ammonia exposure, because ammonia molecules act as de-doping agents to reduce the carrier concentration in polythiophene-based OSCs [22,23]. 
Figure 3. The current densities as a function of the applied bias ( $\mathrm{J}-\mathrm{V})$ of the (a) PQT-12 VNJ-diode and (b) the P3HT VNJ-diode before ammonia sensing (solid line) and after 200-s, 500-ppb ammonia sensing (dashed line).
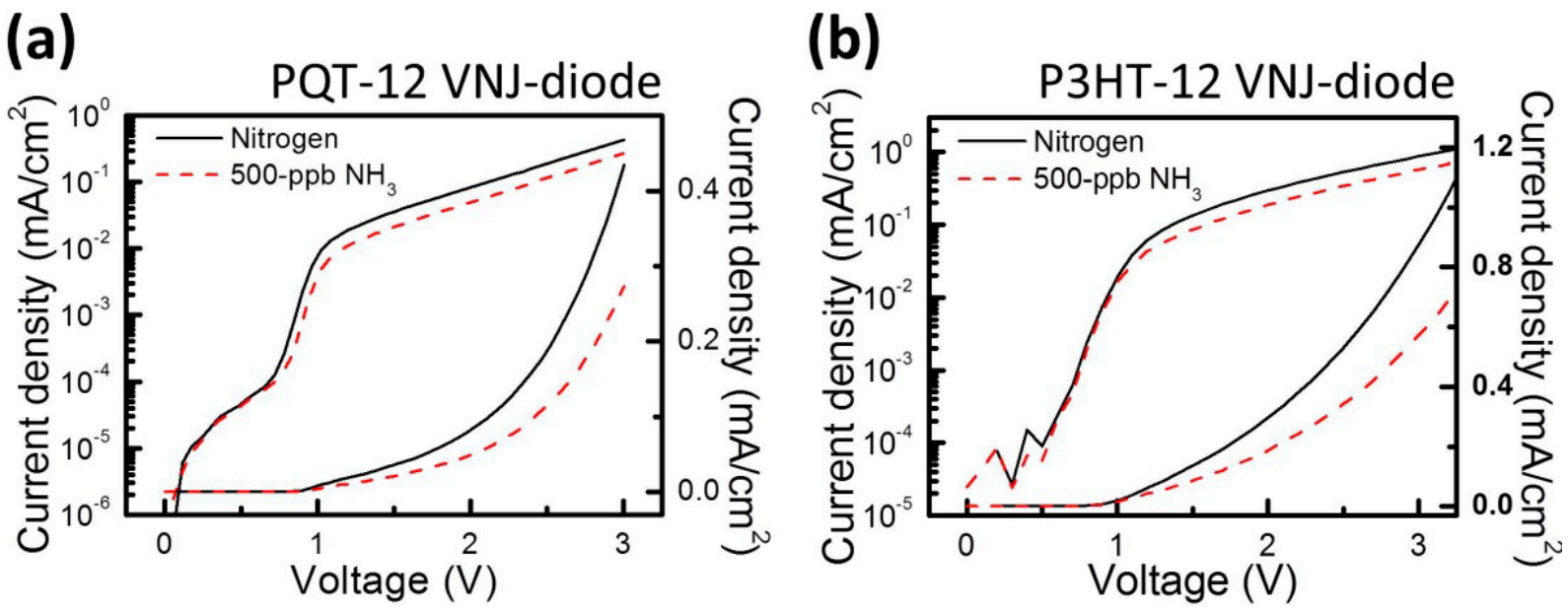

The real-time current variations of fresh PQT-12 VNJ-diode when detecting 500-ppb ammonia are shown in Figure 4a. Four devices fabricated in different runs were measured. When 500-ppb ammonia is injected into the sensing chamber (marked by the triangle symbols), a significant current drop is observed. After removing the ammonia (marked by the star symbols), the current drop can be recovered after about 800-1000 s. The sensing and recovery responses can be repeatedly obtained when 500-ppb ammonia is injected into and removed from the sensing chamber repeatedly. It is noted that devices exhibit device-to-device variation, because of the slightly difference in P3HT film thickness and nanopore density on the top electrode. Such a device-to-device variation, however, can be greatly suppressed when using a current variation ratio to represent the sensing response, as shown in Figure $4 \mathrm{~b}$. The current variation ratio, $\left(I-I_{0}\right) / I_{0}$, is defined as the current minus the initial current $\left(I_{0}\right)$ divided by $I_{0}$. The responses of four devices are all about $42 \%$ under exposure of ammonia for $200 \mathrm{~s}$. With a long enough recovering time (e.g., $800 \mathrm{~s}$ ), an almost full recovery can be obtained (as shown in Figure 4a). Finally, with a fixed reading time of $200 \mathrm{~s}$, the sensing response of the fresh PQT-12 VNJ-diode as a function of ammonia concentration is shown in Figure 4c. Data with error bars were obtained from four independent devices. A detection limit of $50 \mathrm{ppb}$ ammonia is obtained in the proposed device. Data obtained from the fresh P3HT VNJ-diode are also represented by the dashed line in Figure 4c. The relationship between the response of VNJ-diode and ammonia concentration is not a linear relationship, but closer to a power-law relationship [24,25].

So far, we show that the proposed PQT-12 and P3HT VNJ-diodes can detect ammonia molecules in the ppb-regime. The lifetime of P3HT in air, however, is known to be limited. When the P3HT VNJ-diode is exposed to air for two days, the sensor current exhibits a five-times increase at a 2-V bias, and the response to 500-ppb ammonia becomes unstable (shown later in Figure 5d). For real applications, the sensor stability in air needs to be improved. Here, we demonstrate a good air-stability in the OSC-based gas sensor by using PQT-12 to serve as the sensing layer. PQT-12 exhibits the same conjugated backbone as $\mathrm{P} 3 \mathrm{HT}$, but has a better immunity to the humidity-related oxidation in air [26,27]. The J-V curves of the fresh and aged PQT-12 VNJ-diode are shown in Figure 5a. The black $\mathrm{J}-\mathrm{V}$ curve is measured right after fabricating the device. Red, green and blue $\mathrm{J}-\mathrm{V}$ curves are 
measured after putting the PQT-12 VNJ-diode in air for 2, 10 and 25 days, respectively. In Figure 5a, the J-V curves of the PQT-12 VNJ-diode change a bit after being stored in air for several days. However, such a change in the $\mathrm{J}-\mathrm{V}$ curve does not significantly influence the sensor response to ammonia. The responses of the fresh and aged sensor as a function of sensing time to the 500-ppb and 50-ppb ammonia concentrations are shown in Figure 5b,c, respectively. The dashed line represents the recovery behavior after removing ammonia from the micro-fluid system.

Figure 4. (a) The real-time current variations of the fresh PQT-12 VNJ-diode when detecting 500-ppb ammonia. Triangle symbols and star symbols mark the injection and the removal of 500-ppb ammonia, respectively; (b) The sensing response of the four devices; and (c) the response of the fresh PQT-12 VNJ-diode and the P3HT VNJ-diode as a function of ammonia concentration.
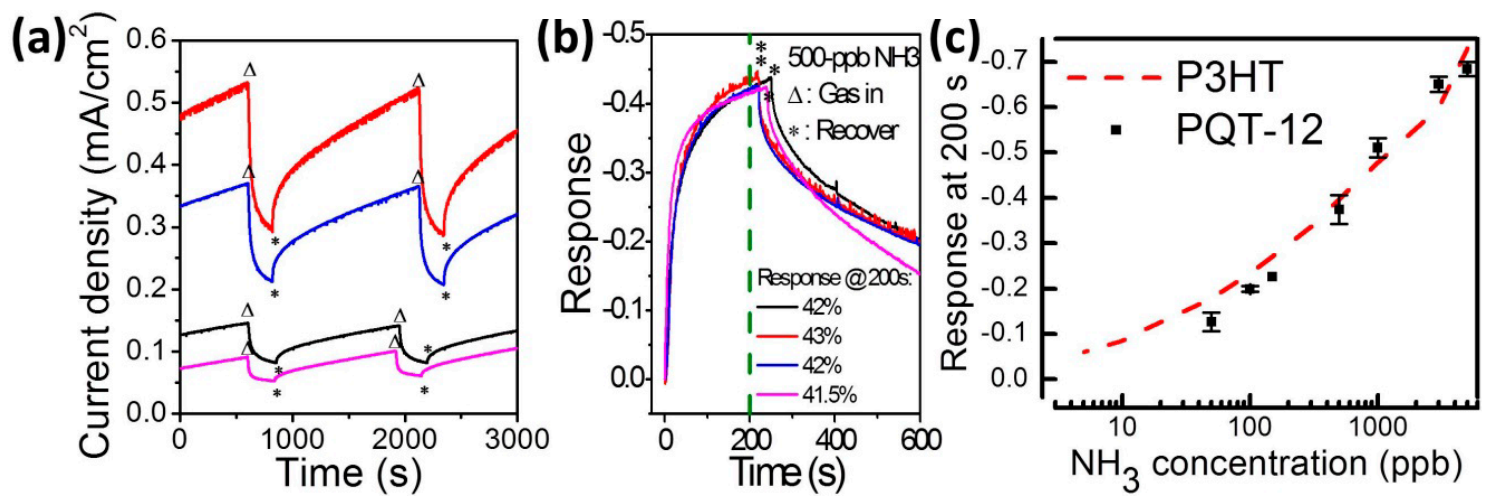

Figure 5. (a) The J-V curves of the fresh and aged PQT-12 VNJ-diode. The responses of the fresh and aged sensor as a function of sensing time to (b) 500-ppb and (c) 50-ppb ammonia. (d) The sensor lifetimes of the P3HT VNJ-diode and the PQT-12 VNJ-diode.

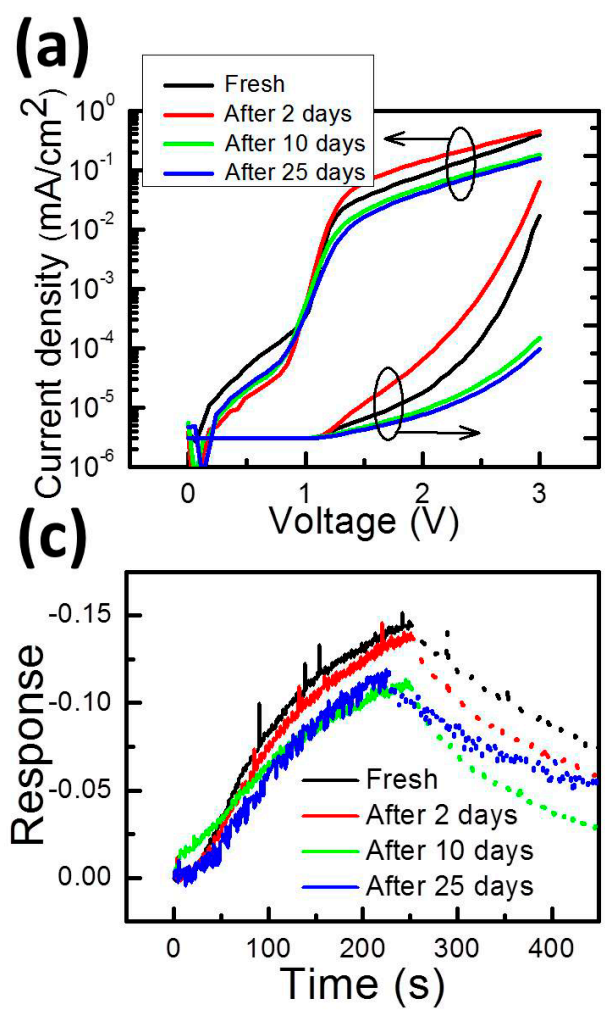

(b)

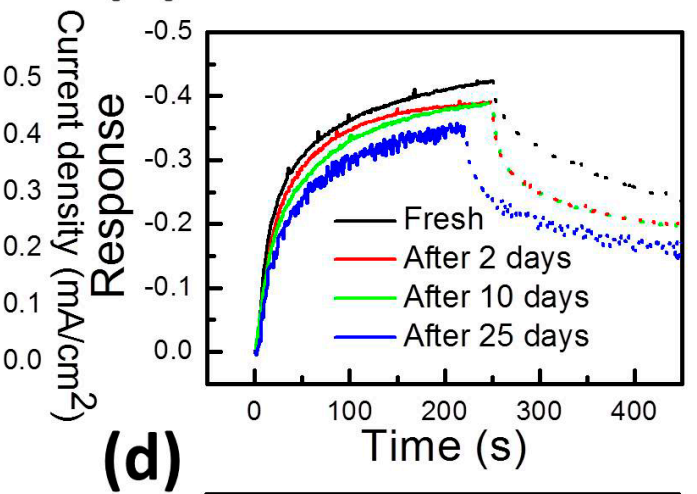

(d)

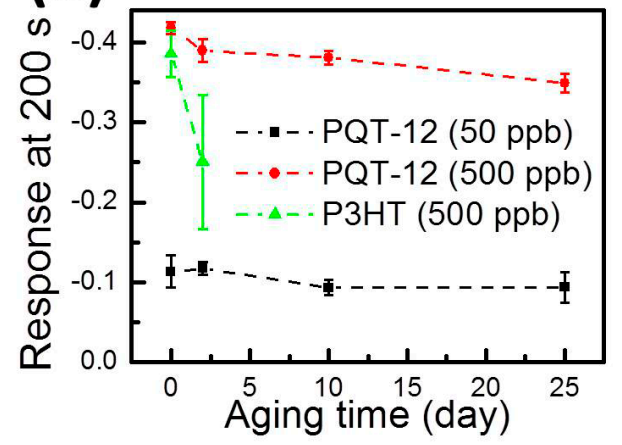


The sensor lifetimes of the P3HT VNJ-diode and the PQT-12 VNJ-diode are compared in Figure 5d. The sensors response readings at $200 \mathrm{~s}$ are plotted as a function of aging time. The P3HT VNJ-diode fails to deliver a stable response to 500-ppb ammonia after being stored in air for two days. For the PQT-12 VNJ-diode, quantitatively speaking, the responses to 500-ppb ammonia are -0.41 and -0.35 for the fresh sensor and the 25-day aged sensor. The responses to 50-ppb ammonia are -0.13 and -0.11 for the fresh sensor and 25 -day aged sensor. About a $15 \%-16 \%$ degradation is observed after 25 days. However, a clear difference between the responses to the 50-ppb and 500-ppb ammonia concentrations can still be obtained. In particular, for low-concentration applications, such as breath ammonia detection [6], the PQT-12 VNJ-diode is able to detect 50-ppb ammonia with an almost unchanged response after being stored 25 days in air.

\section{Conclusions}

In conclusion, this study presents a sensitive ammonia sensor based on an air-stable organic vertical diode. It is known that many organic semiconductor materials suffer from a short lifetime in air due to the oxidation effect between oxygen, moisture and organic molecules. In this work, we investigated the lifetime of an organic-based ammonia sensor in air. The proposed sensitive ammonia sensor exhibited numerous vertical nanometer junctions (VNJ). Two kinds of polythiophene materials, P3HT and air-stable PQT-12, were used as the organic sensing layer. Using low-cost colloidal lithography (i.e., using self-assembled PS nanospheres as a hard mask), a porous top electrode was fabricated to allow ammonia molecules to diffuse easily into the bulk of the polythiophene sensing layer. The bulk current flowing through vertical nano-junctions (VNJ) was decreased due to the de-doping reaction between ammonia and the polythiophene material. When the P3HT VNJ-diode exhibits a detection limit to 50-ppb ammonia, after two days of being stored in air, the P3HT VNJ-diode becomes unstable due to the oxidation effect. On the other hand, the PQT-12 VNJ-diode exhibits a detection limit of 50 -ppb ammonia after being stored in air for 25 days. It emerged that, during the 25-day storage time, the current of the PQT-12 VNJ-diode (biased at $2 \mathrm{~V}$ ) changes significantly (i.e., from 0.13 to $0.04 \mathrm{~mA} / \mathrm{cm}^{2}$ ). The response to $50-\mathrm{ppb}$ ammonia, represented by the current variation ratio, remained almost unchanged during the 25 storage days (i.e., from 0.13 to 0.11 ). Along with the simple structure and low-cost process, the improved air stability demonstrated in this work facilitates future commercialization of OSC-based gas sensors. In our previous work, we already demonstrated that the proposed polythiophene sensor exhibits a significant response to ammonia and has almost no response to carbon dioxide, acetone and ethanol [19]. In future work, it is expected that the proposed sensor may also be able to detect other kinds of amine-based gas molecules for applications in environmental air pollution detection. Furthermore, by using different kinds of sensing materials in the proposed sensor, we may form a sensing array to further improve the sensing selectivity, as well as the sensing sensitivity.

\section{Acknowledgments}

This work was supported in part by the National Science Council under Grant NSC-100-2628-E-009-018-MY3 and in part by Veterans General Hospitals and University System of Taiwan Joint Research Program under Grant VGHUST100-G5-1-1, VGHUST100-G5-1-3 and VGHUST102-G5-1-2. 


\section{Author Contributions}

Ming-Zhi Dai and Yen-Ho Chen did the experiment. Ming-Yen Chuang prepared the paper. Hsiao-Wen Zan supervised the experimental concept, experimental detail, and the paper writing. Hsin-Fei Meng provided suggestions to the explanation and the measurement system.

\section{Conflicts of Interest}

The authors declare no conflict of interest.

\section{References and Notes}

1. Timmer, B.; Olthuis, W.; Berg, A.V.D. Ammonia sensors and their applications-A review. Sens. Actuators B Chem. 2005, 107, 666-677.

2. Toal, S.J.; Trogler, W.C. Polymer sensors for nitroaromatic explosives detection. J. Mater. Chem. 2006, 16, 2871-2883.

3. Jung, J.Y.; Lee, C.S. Characteristics of the $\mathrm{TiO}_{2} / \mathrm{SnO}_{2}$ thick film semiconductor gas sensor to determine fish freshness. J. Ind. Eng. Chem. 2011, 17, 237-242.

4. Lin, P.; Yan, F. Organic thin-film transistors for chemical and biological sensing. Adv. Mater. 2012, 24, 34-51.

5. Tisch, U.; Haick, H. Nanomaterials for cross-reactive sensor arrays. MRS Bull. 2010, 35, 797-803.

6. Hibbard, T.; Killard, A.J. Breath ammonia analysis: Clinical application and measurement. Crit. Rev. Anal. Chem. 2011, 41, 21-35.

7. Wang, L.; Fine, D.; Sharma, D.; Torsi, L.; Dodabalapur, A. Nanoscale organic and polymeric field-effect transistors as chemical sensors. Anal. Bioanal. Chem. 2006, 384, 310-321.

8. Sirringhaus, H. Reliability of organic field-effect transistors. Adv. Mater. 2009, 21, 3859-3873.

9. Hoshino, S.; Yoshida, M.; Uemura, S.; Kodzasa, T.; Takada, N.; Kamata, T.; Yase, K. Influence of moisture on device characteristics of polythiophene-based field-effect transistors. J. Appl. Phys. 2004, 95, 5088-5093.

10. Jeong, H.G.; Lim, B.; Khim, D.; Han, M.; Lee, J.; Kim, J.; Yun, J.M.; Cho, K.; Park, J.W.; Kim, D.Y. A novel thermally reversible soluble-insoluble conjugated polymer with semi-fluorinated alkyl chains: Enhanced transistor performance by fluorophobic self-organization and orthogonal hydrophobic patterning. Adv. Mater. 2013, 25, 6416-6422.

11. Chen, W.N.; Chu, D.P.; Li, S.P. Air stable complementary polymer circuits fabricated in ambient condition by inkjet printing. Org. Electron. 2012, 13, 98-103.

12. Chabinyc, M.L.; Street, R.A.; Northrup, J.E. Effects of molecular oxygen and ozone on polythiophene-based thin-film transistors. Appl. Phys. Lett. 2007, 90, doi:10.1063/1.2715445.

13. Zhang, T.; Nix, M.B.; Yoo, B.Y.; Deshusses, M.A.; Myung, N.V. Electrochemically functionalized single-walled carbon nanotube gas sensor. Electroanalysis 2006, 18, 1153-1158.

14. Penza, M.; Rossi, R.; Alvisi, M.; Cassano, G.; Signore, M.A.; Serra, E.; Giorgi, R. Pt- and Pd-nanoclusters functionalized carbon nanotubes networked films for sub-ppm gas sensors. Sens. Actuators B Chem. 2008, 135, 289-297. 
15. Rigoni, F.; Tognolini, S.; Borghetti, P.; Drera, G.; Pagliara, S.; Goldoni, A.; Sangaletti, L. Enhancing the sensitivity of chemiresistor gas sensors based on pristine carbon nanotubes to detect low-ppb ammonia concentrations in the environment. Analyst 2013, 138, 7392-7399.

16. Li, X.B.; Ma, S.Y.; Li, F.M.; Chen, Y.; Zhang, Q.Q.; Yang, X.H.; Wang, C.Y.; Zhu, J. Porous spheres-like $\mathrm{ZnO}$ nanostructure as sensitive gas sensors for acetone detection. Mater. Lett. 2013, 100, 119-123.

17. Chen, G.; Paronyan, T.M.; Pigos, E.M.; Harutyunyan, A.R. Enhanced gas sensing in pristine carbon nanotubes under continuous ultraviolet light illumination. Sci. Rep. 2012, 2, doi:10.1038/srep00343.

18. Hassan, J.J.; Mahdi, M.A.; Chin, C.W.; Abu-Hassan, H.; Hassan, Z. A high-sensitivity room-temperature hydrogen gas sensor based on oblique and vertical $\mathrm{ZnO}$ nanorod arrays. Sens. Actuators B Chem. 2013, 176, 360-367.

19. Dai, M.Z.; Lin, Y.L.; Lin, H.C.; Zan, H.W.; Chang, K.T.; Meng, H.F.; Liao, J.W.; Tsai, M.J.; Cheng, H. Highly sensitive ammonia sensor with organic vertical nanojunctions for noninvasive detection of hepatic injury. Anal. Chem. 2013, 85, 3110-3117.

20. Vieira, S.M.C.; Beecher, P.; Haneef, I.; Udrea, F.; Milne, W.I.; Namboothiry, M.A.G.; Carroll, D.L.; Park, J.; Maeng, S. Use of nanocomposites to increase electrical "gain" in chemical sensors. Appl. Phys. Lett. 2007, 91, doi:10.1063/1.2811716.

21. The P3HT VNJ-diode characteristics simulation is made based on the device structure shown in Figure 1b. The thicknesses P3HT and Al are 42.5 and $40 \mathrm{~nm}$, respectively. The opening diameter is $200 \mathrm{~nm}$. The highest occupied molecular orbital and lowest unoccupied molecular orbital levels of P3HT are 5.1 and $3.0 \mathrm{eV}$. The work functions of ITO and Al are 5.0 and $4.3 \mathrm{eV}$. The hole mobility and electron mobility in P3HT are $1 \times 10^{-7}$ and $1 \times 10^{-10} \mathrm{~cm}^{2} / \mathrm{V} \cdot \mathrm{s}$.

22. Jeong, J.W.; Lee, Y.D.; Kim, Y.M.; Park, Y.W.; Choi, J.H.; Park, T.H.; Soo, C.D.; Won, S.M.; Han, I.K.; Ju, B.K. The response characteristics of a gas sensor based on poly-3-hexylithiophene thin-film transistors. Sens. Actuators B Chem. 2010, 146, 40-45.

23. Mohammad, F. Compensation behaviour of electrically conductive polythiophene and polypyrrole. J. Phys. D Appl. Phys. 1998, 31, 951-959.

24. Aguilar, A.D.; Forzani, E.S.; Nagahara, L.A.; Amlani, I.; Tsui, R.; Tao, N.J. Breath ammonia sensor based on conducting polymer nanojunctions. IEEE Sens. J. 2008, 8, 269-273.

25. Comes, P.; Gonzalez-Flesca, N.; Bader, F.; Grimalt, J.O. Langmuirian behaviour of smelly volatile organic compounds on air sampling with solid adsorbents. J. Chromatogr. A 1996, 723, 293-299.

26. Ong, B.S.; Wu, Y.; Liu, P.; Gardner, S. High-performance semiconducting polythiophenes for organic thin-film transistors. J. Am. Chem. Soc. 2004, 126, 3378-3379.

27. Ong, B.S.; Wu, Y.; Liu, P.; Gardner, S. Structurally ordered polythiophene nanoparticles for high-performance organic thin-film transistors. Adv. Mater. 2005, 17, 1141-1144.

(C) 2014 by the authors; licensee MDPI, Basel, Switzerland. This article is an open access article distributed under the terms and conditions of the Creative Commons Attribution license (http://creativecommons.org/licenses/by/3.0/). 